Article

\title{
Supercritical Extraction of Lycopene from Tomato Industrial Wastes with Ethane
}

\author{
Beatriz P. Nobre ${ }^{1,2, *}$, Luisa Gouveia ${ }^{1}$, Patricia G. S. Matos ${ }^{2}$, Ana F. Cristino ${ }^{2,3}$, \\ António F. Palavra ${ }^{2}$ and Rui L. Mendes ${ }^{1}$ \\ 1 Unidade de Bioenergia, LNEG, Estrada do Paço do Lumiar, 1649-038 Lisboa, Portugal \\ 2 Centro Química Estrutural, DEQB, IST, Av. Rovisco Pais, 1, 1049-001 Lisboa, Portugal \\ 3 Centro de Ciências Moleculares e Materiais, DQB, FCUL, Campo Grande, 1749-016 Lisboa, Portugal \\ * Author to whom correspondence should be addressed; E-Mail: Beatriz.nobre@ist.utl.pt; \\ Tel.: +351-218-419-070; Fax: +351-218-464-455.
}

Received: 1 May 2012; in revised form: 3 July 2012 / Accepted: 5 July 2012 /

Published: 11 July 2012

\begin{abstract}
Supercritical fluid extraction of all-E-lycopene from tomato industrial wastes (mixture of skins and seeds) was carried out in a semi-continuous flow apparatus using ethane as supercritical solvent. The effect of pressure, temperature, feed particle size, solvent superficial velocity and matrix initial composition was evaluated. Moreover, the yield of the extraction was compared with that obtained with other supercritical solvents (supercritical $\mathrm{CO}_{2}$ and a near critical mixture of ethane and propane). The recovery of all-E-lycopene increased with pressure, decreased with the increase of the particle size in the initial stages of the extraction and was not practically affected by the solvent superficial velocity. The effect of the temperature was more complex. When the temperature increased from 40 to $60{ }^{\circ} \mathrm{C}$ the recovery of all-E-lycopene increased from 80 to $90 \%$. However, for a further increase to $80{ }^{\circ} \mathrm{C}$, the recovery remained almost the same, indicating that some $E-Z$ isomerization could have occurred, as well as some degradation of lycopene. The recovery of all- $E$-lycopene was almost the same for feed samples with different all- $E$-lycopene content. Furthermore, when a batch with a higher all-E-lycopene content was used, supercritical ethane and a near critical mixture of ethane and propane showed to be better solvents than supercritical $\mathrm{CO}_{2}$ leading to a faster extraction with a higher recovery of the carotenoid.
\end{abstract}

Keywords: carotenoids; ethane; lycopene extraction; supercritical fluid 


\section{Introduction}

Carotenoids include more than 750 compounds, representing one of the major natural coloring groups, that are responsible for the yellow, orange and red colors of many fruits, vegetables, flowers, fungi, algae and some animals. Lycopene is a lipid soluble carotenoid $\left(\mathrm{C}_{40} \mathrm{H}_{56}\right)$ which presents $Z$ - $($ cis $)$ and $E$-(trans) geometrical isomers due to the presence of the methyl groups bonded to a polyenic chain. It is responsible for the red color of tomato and its based products, being the major carotenoid present in this fruit. Other available natural sources of this compound include watermelon, apricot, papaya, guava, pink grape-fruit, pumpkins and rosehip fruit [1-5]. On the other hand, some microorganisms have been reported in the last years as a promising source of this carotenoid [6,7].

Lycopene's major commercial use is as a colouring agent in the feed, food, nutraceutical and pharmaceutical industries [8], although its biological properties, as anti-oxidant and anti-carcinogenic agent, have been gaining increased attention in the last decade [9]. Due to this fact, lycopene consumption is strongly recommended for reducing the risk of atherosclerosis, coronary heart diseases and some types of cancer [10].

Commercially available lycopene is mainly obtained by extraction and purification of tomatoes using hexane and ethyl acetate as solvents or by chemical synthesis [11], although some lycopene-producing microorganisms are also being used on a smaller scale [6,7]. Lycopene content in tomatoes can vary greatly, depending on environmental factors, agricultural techniques and tomato types [12,13], with values ranging between 10 and $200 \mathrm{mg} / \mathrm{kg}$ (wet basis). Most of the compound is located in the insoluble fraction with the skin containing five times more lycopene than the pulp $[10,14,15]$. On the other hand, the lycopene bioavailability increases with cooking (heating) and smashing of the vegetable matrices [16].

Tomato industries produce large amounts of solid wastes, up to 3-4\% of the processed fruit [17], consisting mainly of skins and seeds. As a consequence, most of the original lycopene in tomatoes is wasted. On the other hand, these solid residues are frequently used, without further treatment, as animal feed. Therefore, the extraction of this valuable compound could be a good alternative to the valorization of this by-product $[18,19]$.

Supercritical fluid extraction of compounds with interest in the food and nutraceutical industries has received increased attention in the past three decades. It presents important advantages over the conventional organic extraction, such as reducing the use of toxic solvents, the possibility to work at moderate temperatures avoiding thermal degradation of the carotenoids, obtaining a solvent free extract, higher selectivity and in some cases higher yields. Carbon dioxide is the most used supercritical solvent due to its well described properties [20], but other solvents like ethane or propane have also being successfully applied $[21,22]$. The use of ethane instead of $\mathrm{CO}_{2}$ as supercritical solvent for the food industry may offer several advantages, since ethane, although being more expensive than $\mathrm{CO}_{2}$, has a low critical temperature, near that of supercritical $\mathrm{CO}_{2}$ and a low critical pressure $(305.4 \mathrm{~K}$ and $48.2 \mathrm{~atm}$ [23]) which will allow reducing the energy costs associated to the process [21]. On the other hand, ethane is an apolar solvent, with a higher polarizability than $\mathrm{CO}_{2}$ [20], which makes it presumably a better solvent for the type of carotenoids found in tomato.

Supercritical fluid extraction of lycopene from tomato industrial wastes has been recently proposed as an alternative technology [24-32]. Baysal et al. [25] studied the extraction of lycopene and 
$\beta$-carotene from the by-products of the tomato industry, using supercritical $\mathrm{CO}_{2}$. These authors evaluated the effect of pressure, temperature, time of extraction, solvent flow-rate and addition of co-solvent (ethanol). The maximum recovery of lycopene, $54 \%$, was obtained at $55{ }^{\circ} \mathrm{C}$ and 300 bar with the addition of 5\% (vol.) ethanol as co-solvent. Rozzy et al. [24] also extracted lycopene from tomato residues with supercritical $\mathrm{CO}_{2}$ and obtained as best extraction conditions $56{ }^{\circ} \mathrm{C}$ and 344.7 bar, obtaining $61 \%$ of the total lycopene. Sábio et al. [28] obtained a recovery of lycopene of $80 \%$, from the skins and seeds of tomatoes, using supercritical $\mathrm{CO}_{2}$ at $60{ }^{\circ} \mathrm{C}$ and 300 bar. Ollanket et al. [31] achieved $100 \%$ recovery of lycopene with supercritical $\mathrm{CO}_{2}$ at $110{ }^{\circ} \mathrm{C}$ and 400 bar. Favati et al. [26] obtained a recovery of $64 \%$ of lycopene from industrial tomato wastes using supercritical $\mathrm{CO}_{2}$ modified with sunflower oil, at $80{ }^{\circ} \mathrm{C}$ and 500 bar. Furthermore, Vasapollo et al. [27] extracted a maximum of $60 \%$ of lycopene from tomato with $\mathrm{CO}_{2}$, at 450 bar and $66{ }^{\circ} \mathrm{C}$, using hazelnut oil as co-solvent. The published data show that supercritical fluid extraction is suitable for the extraction of lycopene from tomato industrial wastes. Nevertheless, to the best of our knowledge, none of the published studies deals with the use of ethane as supercritical solvent.

The objective of this work was to study the effect of several parameters (pressure, temperature, solvent superficial velocity, particle size and matrix initial composition) on the extraction of all-E-lycopene from tomato industrial wastes using supercritical ethane. The comparison of the recovery of all-E-lycopene using other solvents (supercritical $\mathrm{CO}_{2}$ [32] and a near critical mixture of ethane and propane) was also carried out.

\section{Results and Discussion}

\subsection{Effect of Matrix Composition}

Two tomato paste waste matrices, M1 and M2, with different all- $E$-lycopene contents (M1-127 $\mu \mathrm{g} / \mathrm{g}$ dry matter; M2 - $213 \mu \mathrm{g} / \mathrm{g}$ dry matter), were submitted to supercritical ethane extraction at temperature of $60{ }^{\circ} \mathrm{C}$, pressure of 300 bar and solvent superficial velocity of $1.44 \mathrm{~cm} / \mathrm{min}$.

Figure 1 shows the recovery (mass of extracted compound by supercritical fluid extraction/mass of extracted compound by Soxhlet $\times 100$ ) of all-E-lycopene from the two matrices, M1 and M2. It can be seen that the recovery of all-E-lycopene is almost the same for both matrices. This behavior is different than that obtained with supercritical $\mathrm{CO}_{2}$, in which matrices with higher lycopene content showed a slower extraction rate and a lower recovery of the carotenoid [32]. The extraction curves show that in the first period of the extraction (when the process is possibly controlled by the equilibrium between the supercritical ethane and the solutes in the solid matrix) almost all the lycopene is extracted. The higher solubility of lycopene in ethane (when compared with that in $\mathrm{CO}_{2}$ ) will allow a faster extraction. For the matrix with higher lycopene content possibly a higher amount of lycopene is accessible to the solvent and so more carotenoid will be extracted. 
Figure 1. Recovery of all- $E$-lycopene as a function of ethane amount, at $60{ }^{\circ} \mathrm{C}, 300 \mathrm{bar}$, matrix particle size of $0.36 \mathrm{~mm}$ and solvent superficial velocity of $1.44 \mathrm{~cm} / \mathrm{min}$, for the two tomato waste matrices tested (M1 and M2).

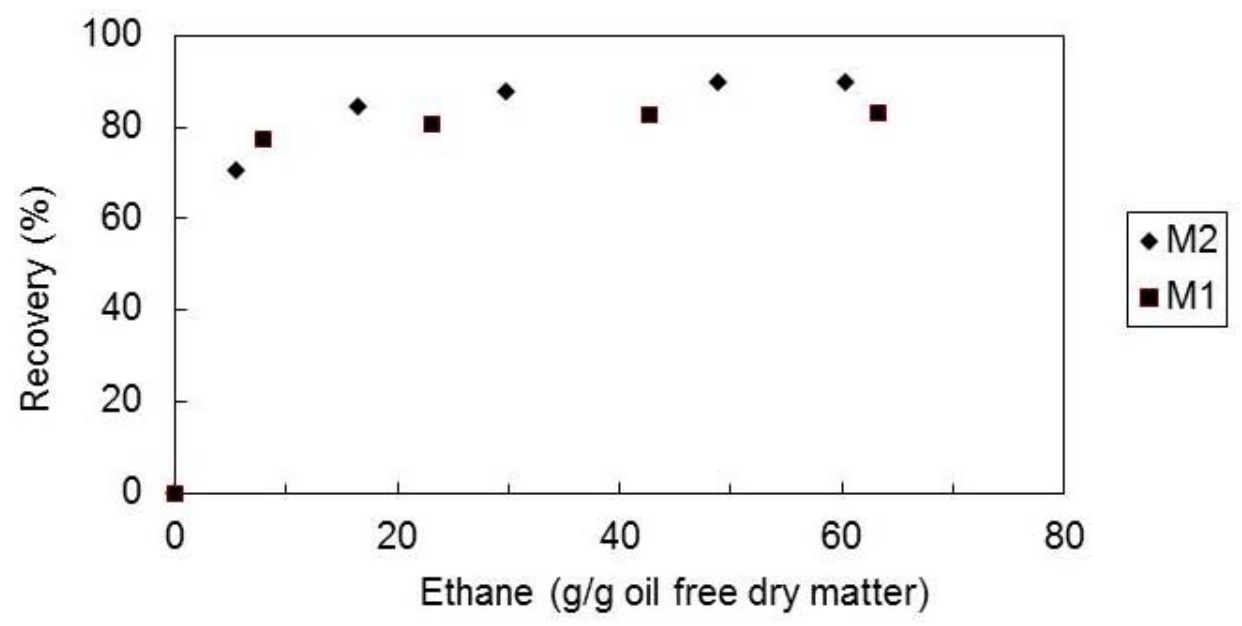

\subsection{Effect of the Supercritical Solvent}

The sample of tomato paste waste M2 was also submitted to supercritical fluid extraction using supercritical $\mathrm{CO}_{2}$ [32] and a near critical mixture of ethane and propane. In Figure 2 the obtained recoveries are shown. It was verified that the mixture of ethane/propane led to the higher recovery (about $100 \%$ ) of all-E-lycopene, followed by ethane (90\%) and $\mathrm{CO}_{2}$ [32] (86\%). Also the extraction was faster when ethane and the mixture of ethane and propane were used. This behavior could be explained in terms of the solubility of the compound in the supercritical solvent which will be higher in ethane and in the mixture of ethane + propane than in $\mathrm{CO}_{2}$. Suogi et al. [29] carried out supercritical fluid extraction of lycopene from tomato industrial wastes using $\mathrm{CO}_{2}$ and propane as solvents and verified that the extraction using propane required a lower amount of solvent than that using $\mathrm{CO}_{2}$. Furthermore, it was possible to work at lower pressures with the former solvent. On the other hand, Nobre et al. [33,34] found also that supercritical ethane and near critical mixtures of ethane and propane were better solvents for $\beta$-carotene (a structural isomer of lycopene) than $\mathrm{CO}_{2}$. Moreover, the solubility of this carotenoid increased with the amount of propane in the mixture of solvents.

\subsection{Effect of the Pressure and Temperature}

The effect of pressure on the recovery of the extraction was also studied. In Figure 3 is represented the recovery of all-E-lycopene from matrix $\mathrm{M} 2$, at temperature of $60{ }^{\circ} \mathrm{C}$, superficial velocity of $1.44 \mathrm{~cm} / \mathrm{min}$ and pressures of 120, 200 and 300 bar. It can be seen that the recovery increases with pressure and rises drastically when the pressure increases from 200 to 300 bar, which is expected due to the increase in the solvent density with pressure. Also, the extraction is much faster at the highest pressure. This could possibly be due to the fact that the extraction of carotenoids occurred only after most of the lipids, mainly triglycerides, were extracted at 200 bar. 
Figure 2. Recovery of all-E-lycopene from sample M2 as a function of solvent amount, at $60{ }^{\circ} \mathrm{C}, 300$ bar, matrix particle size of $0.36 \mathrm{~mm}$ and solvent superficial velocity of $1.44 \mathrm{~cm} / \mathrm{min}$, for the solvents tested.

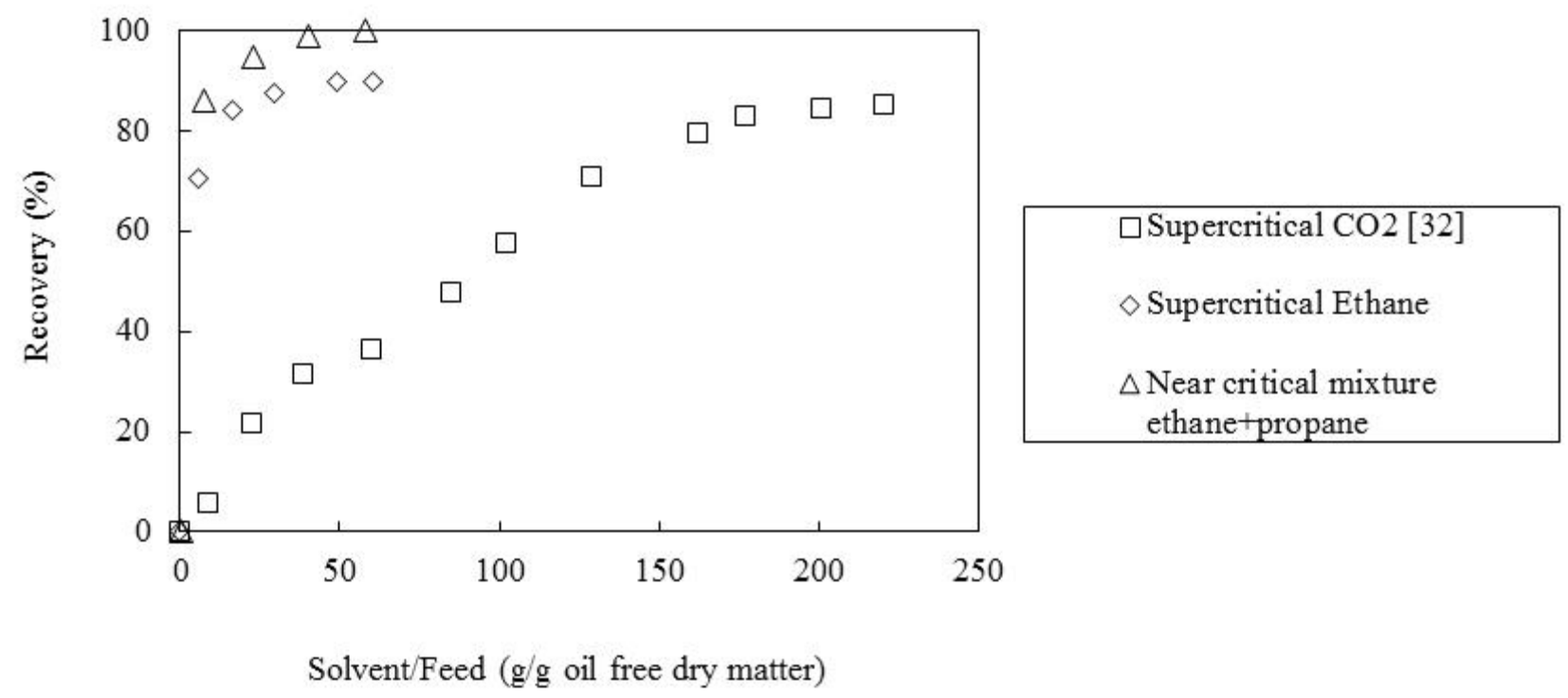

Figure 3. Recovery of all-E-lycopene from sample $M 2$ as a function of solvent amount, at $60{ }^{\circ} \mathrm{C}$, solvent superficial velocity of $1.44 \mathrm{~cm} / \mathrm{min}$ and matrix particle size of $0.36 \mathrm{~mm}$ for the several pressures tested.

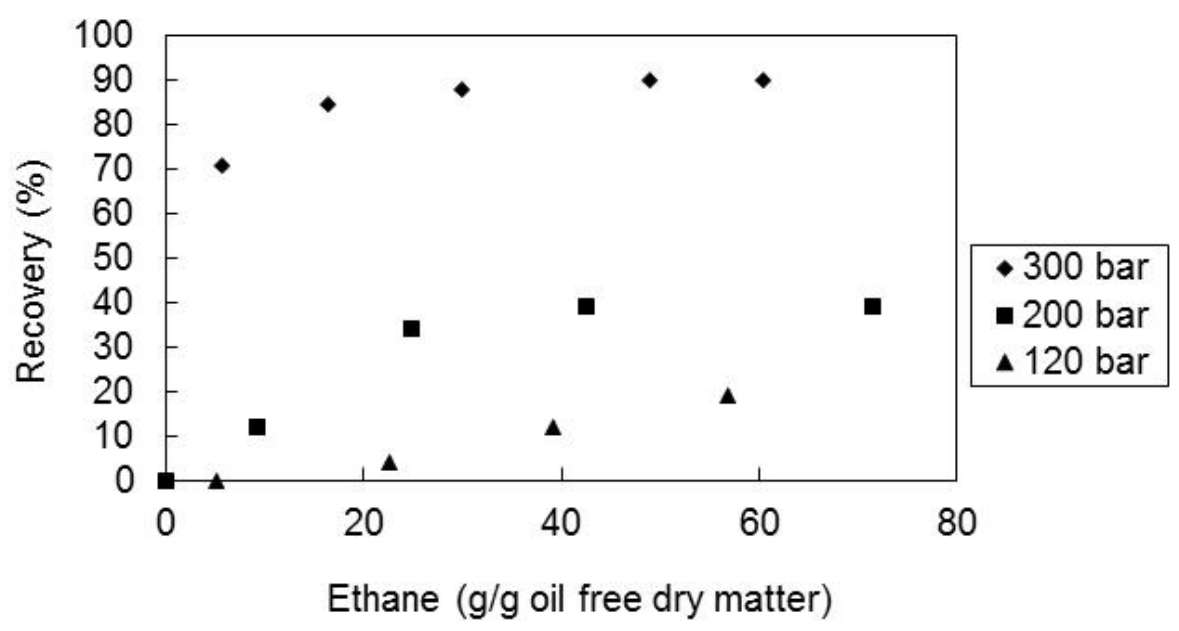

The effect of temperature in the recovery of all- $E$-lycopene was also studied and the results, expressed as recovery of all-E-lycopene versus temperature are represented in Figure 4. It is shown that the recovery of the carotenoid increased slightly when the temperature increased from 40 to $60{ }^{\circ} \mathrm{C}$ and remained almost the same with a further rise of the temperature to $80{ }^{\circ} \mathrm{C}$. That increase is possibly due to some all-E- $>Z$ isomerization occurred at the higher temperature used, since the supercritical extracts showed a higher amount of the $\mathrm{Z}$ isomer at this temperature. 
Figure 4. Recovery of all- $E$-lycopene from sample M2 as a function of solvent amount, at $300 \mathrm{bar}$, solvent superficial velocity of $1.44 \mathrm{~cm} / \mathrm{min}$ and feed particle size of $0.36 \mathrm{~mm}$, for the several temperatures tested.

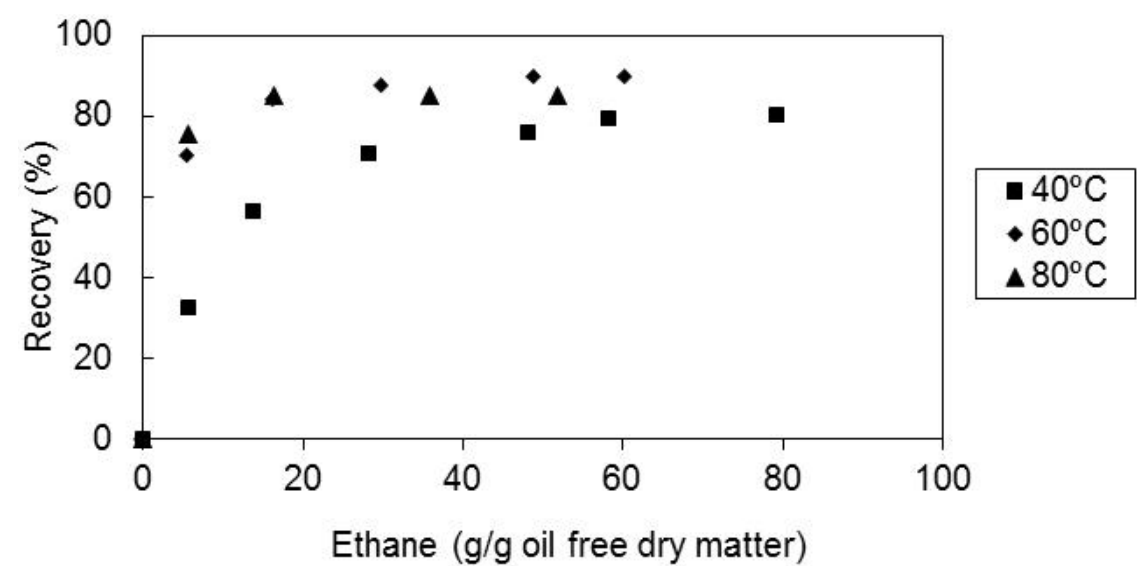

\subsection{Effect of the Solvent Superficial Velocity and Particle Size}

To study the effect of the ethane superficial velocity through the extractor, supercritical fluid extraction experiments were carried out at the temperature of $60^{\circ} \mathrm{C}$, pressure of $300 \mathrm{bar}$, mean particle size of $0.36 \mathrm{~mm}$. Three different solvent superficial velocities were used: $0.63,1.44$ and $2.58 \mathrm{~cm} / \mathrm{min}$.

In Figure 5 are shown the obtained recoveries of $E$-lycopene as a function of the solvent amount. It can be observed that the final recoveries are independent of the three supercritical ethane flowrates, although, in the initial period of extraction the recovery increases slightly when the flow rate decreases.

Figure 5. Recovery of all-E-lycopene from sample $M 2$ as a function of solvent amount, at $60{ }^{\circ} \mathrm{C}, 300$ bar and matrix particle size of $0.36 \mathrm{~mm}$ for the several solvent superficial velocities.

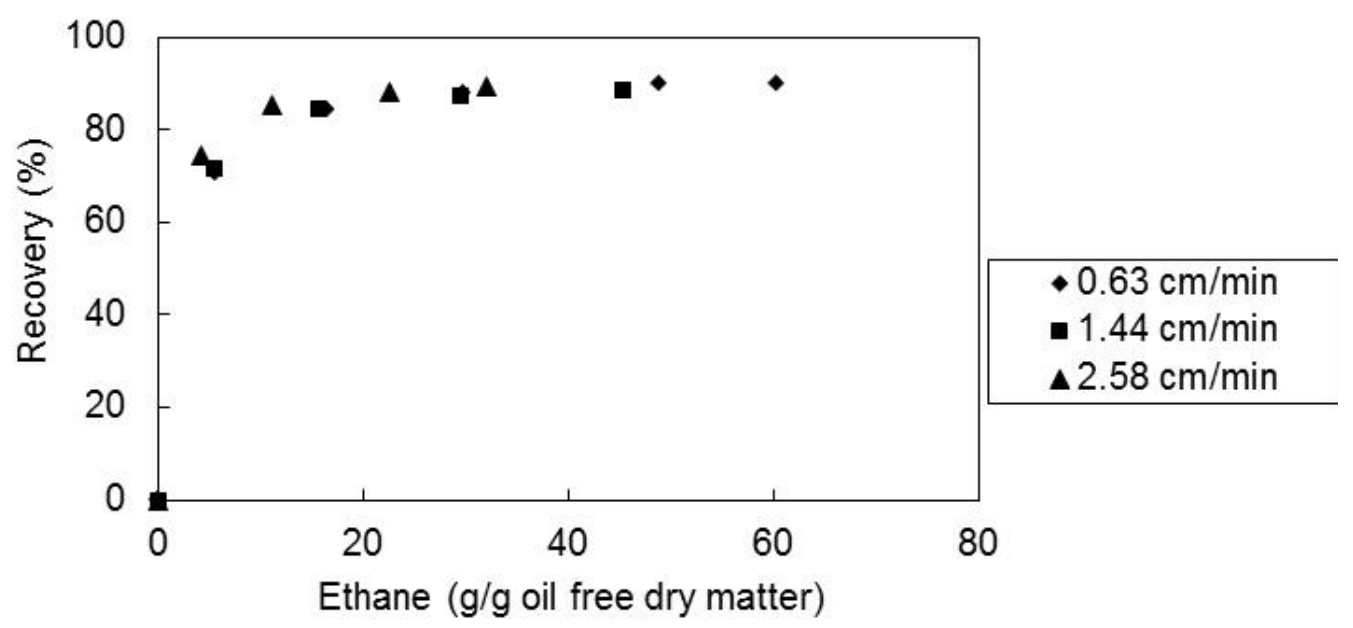

Moreover, the effect of the particle size on the supercritical extraction behaviour was also studied. Three different mean particle size samples of the tomato paste waste $(0.15,0.36$ and $0.56 \mathrm{~mm})$ were used in supercritical fluid extraction with ethane at $60^{\circ} \mathrm{C}$ and 300 bar.

In Figure 6 the recoveries of all-E-lycopene are shown as a function of the solvent amount. It was found that the final recovery of all-E-lycopene is practically independent of the particle sizes used in this work. The reduction of size increased the particle surface area and also can cause ruptures of the 
cell walls becoming the all-E-lycopene more accessible to the supercritical solvent in the initial stages of extraction.

Figure 6. Recovery of all- $E$-lycopene from sample M2 as a function of solvent amount, at $60{ }^{\circ} \mathrm{C}, 300$ bar and solvent superficial velocity of $1.44 \mathrm{~cm} / \mathrm{min}$, for the several matrix particle sizes tested.

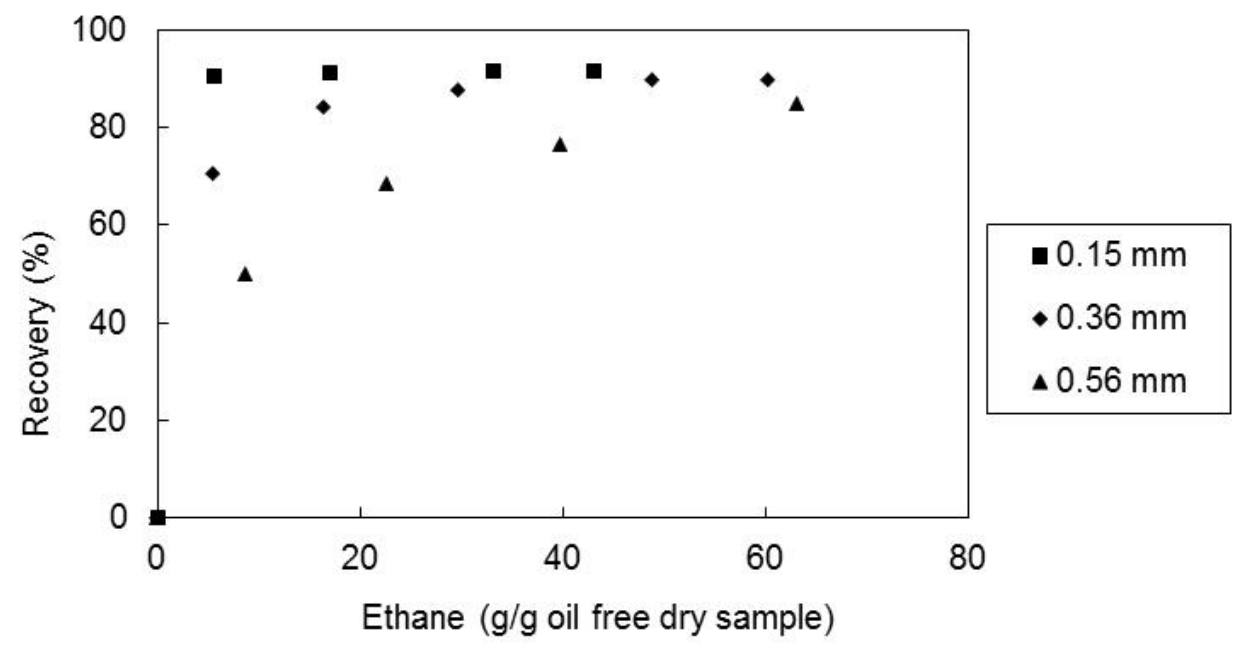

\section{Experimental}

\subsection{Materials}

Ethane (99.998\% purity) was purchased from Air Liquide (Lisbon, Portugal). A solvent mixture of ethane and propane (99.995\% purity) with 50\%/50\% (mole) was obtained from Praxair (Lisbon, Portugal). Tomato industrial wastes (a mixture of skins and seeds) were offered by a local tomato processing company: Fomento da Industria do Tomate SA — FIT. Lycopene standard (90-95\% purity) was purchased from Sigma-Aldrich Chemie Gmbh (Steinheim, Germany). Acetone (p.a.), methanol (HPLC grade), acetonitrile (HPLC grade), and $n$-hexane (p.a) were obtained from Merck (Damstadt, Germany).

\subsection{Sample Preparation}

Two samples of tomato industrial waste were used, M1 and M2. The samples were collected in different occasions and from different types of tomato. Both samples were dried in an oven at the temperature of $40{ }^{\circ} \mathrm{C}$ up to a moisture content of $4.6 \%$. The dried tomato pastes were then packed under nitrogen and stored at $-20{ }^{\circ} \mathrm{C}$. The product was ground prior to the supercritical fluid extraction measurements using a cutting mill and samples with mean particle size of $0.15,0.36$ and $0.56 \mathrm{~mm}$ were used for batch M2 and with particle size of $0.36 \mathrm{~mm}$ for batch M1. The amount of all-E-lycopene of the tomato waste was determined by Soxhlet extraction of $1 \mathrm{~g}$ of ground tomato waste using as solvent a mixture of acetone:hexane (1:1) for 6 hours and quantified by HPLC. The values obtained were: $127 \mu \mathrm{g} / \mathrm{g}$ dry matter for matrix M1 and $213 \mu \mathrm{g} / \mathrm{g}$ dry matter for matrix M2. 


\subsection{Experimental Procedure}

The supercritical measurements were carried out with a flow-type apparatus for the extraction of carotenoids from microalgae, whose details were described before [35]. In this apparatus, the metering pump compresses the liquid solvent to the desired pressure, which was controlled by a back-pressure regulator. In order to guarantee that the fluid reaches the extraction vessel at the desired temperature, the fluid passed through a heat exchanger immersed in a temperature-controlled water bath. After passing the extraction vessel the fluid was expanded to atmospheric pressure through a three-way valve, and the extract precipitates in the glass wool placed inside a glass U-tube, which was immersed in an ice and salt $(\mathrm{NaCl})$ bath at the temperature of $-21^{\circ} \mathrm{C}$. The total time of extraction varied between 3 to $8 \mathrm{~h}$ Gas flowrate was monitored by a rotameter and the total volume of gas was measured with a wet test meter. The $5 \mathrm{~mL}$ extraction vessel had an internal diameter of $7.9 \mathrm{~mm}$, being filled with about $1.5 \mathrm{~g}$ of tomato industrial wastes, packed between two layers of glass wool.

Fractions of 5 to $10 \mathrm{~L}$ of expanded gas were collected along the time. Three solvent superficial velocities were tested: $0.63 \mathrm{~cm} / \mathrm{min}, 1.44 \mathrm{~cm} / \mathrm{min}$ and $2.58 \mathrm{~cm} / \mathrm{min}$ (flowrate of $0.16,0.27$ and $0.41 \mathrm{~g} / \mathrm{min}$ ).

The extracts were collected by washing the glass wool, the inside of the three-way valve and the expansion tubing with acetone. The collected solutions were analyzed by HPLC in order to quantify the amounts of extracted lycopene. The HPLC system consisted of a Hewlett Packard 1100 series liquid chromatograph, with a UV/VIS detector adjusted to $470 \mathrm{~nm}$. A mobile phase of methanol-acetonitrile $(90: 10 \mathrm{v} / \mathrm{v})$ was used at $1 \mathrm{~mL} / \mathrm{min}$ with the reversed phase column, $250 \times 4.6 \mathrm{~mm}$, Vydac $201 \mathrm{TP} 54$. All-E-lycopene was identified by comparing the retention times of the carotenoid with those of the standard compound, which was also used to obtain calibrations curves, in order to determine the total amounts of all-E and Z-lycopene. In Figure 7A,B are shown the chromatograms obtained for the Soxhlet and supercritical fluid extracts, respectively.

Figure 7. HPLC chromatograms of (A) Soxhlet extract; (B) supercritical fluid extraction extract (conditions: $60^{\circ} \mathrm{C}, 300 \mathrm{bar}, 0.36 \mathrm{~mm}$ and $1.44 \mathrm{~cm} / \mathrm{min}$ ). 1-lutein, 2-all- $E$-beta-carotene, 3-Z-beta-carotene, 4-Z-lycopene, 5-all-E-lycopene.

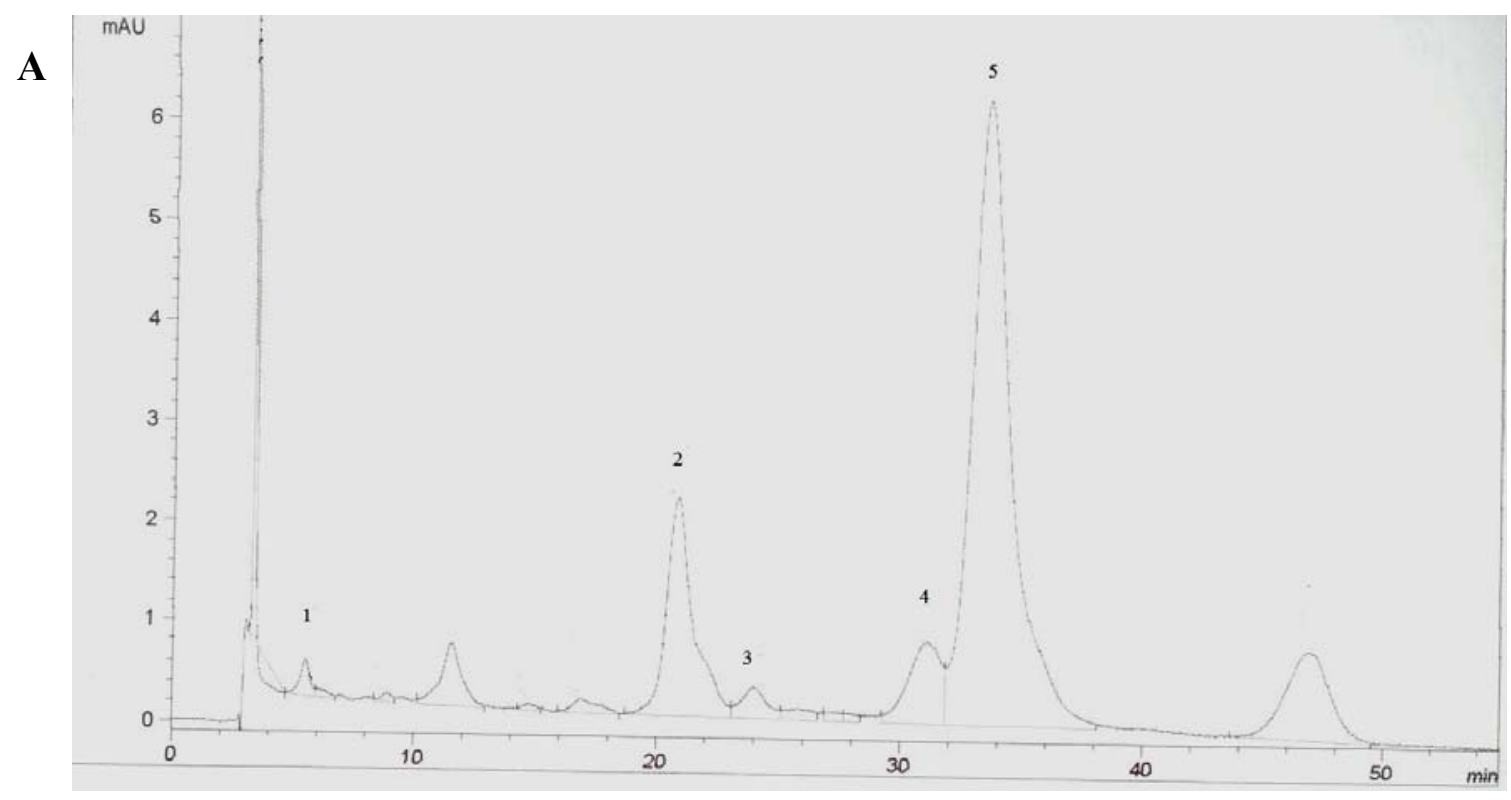


Figure 7. Cont.

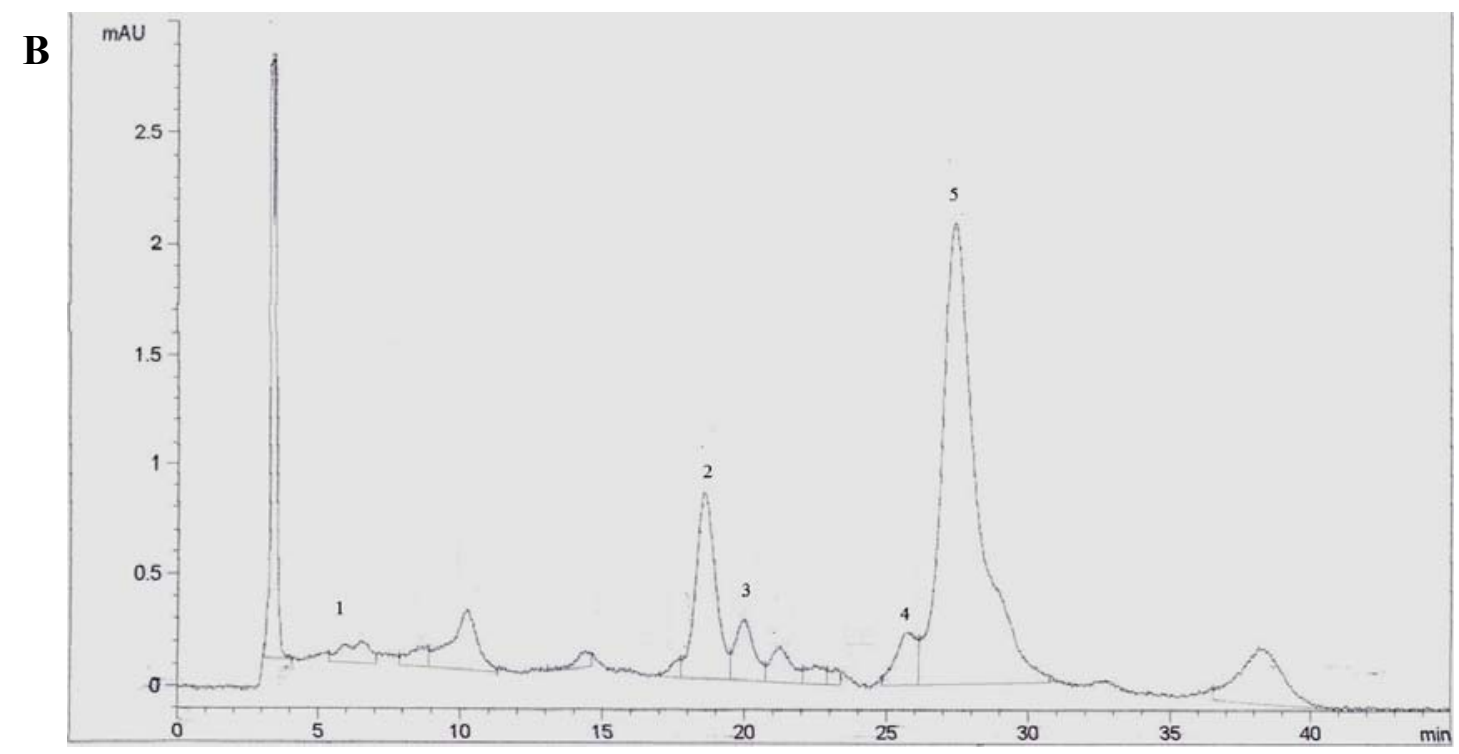

\section{Conclusions}

Tomato industrial wastes (mixture of skins and seeds) were submitted to supercritical ethane in order to extract all-E-lycopene. The recovery of this carotenoid increased with pressure, decreased with the increase of particle size in the initial period of the extraction and was independent of the solvent flow rate. The increase in temperature from 40 to $60{ }^{\circ} \mathrm{C}$ leads to an increase in the recovery of all-E-lycopene. However, for a higher temperature, $80{ }^{\circ} \mathrm{C}$, the recovery remained almost the same, indicating that possibly some all- $E-Z$ isomerization (and also some degradation) could have occurred.

On the other hand, the recovery of lycopene was almost the same for samples with different lycopene content. Furthermore, supercritical ethane and the near critical mixture of ethane and propane showed to be better solvents than supercritical $\mathrm{CO}_{2}$, leading to a faster extraction and a higher recovery of the carotenoid.

\section{Acknowledgements}

Beatriz P. Nobre thanks the Foundation for Science and Technology (FCT Portugal) for the research grant (SFRH/BPD/42004/2007) and FIT-Fomento da Industria do Tomate S.A. for generously supplying the tomato industrial residues. Ana F. Cristino thanks FCT for the Research Grant (SFRH/BD/48596/2008).

\section{References}

1. Perkins-Veazie, P.; Collins, J.K. Flesh quality and lycopene stability of fresh-cut watermelon. Postharvest Biol. Technol. 2004, 31, 159-166.

2. Böhm, V.; Fröhlich, K.; Bitsch, R. Rosehip_A "new" source of lycopene? Mol. Aspects Med. 2003, 24, 385-389. 
3. Pol, J.; Hyitylainen, T.; Ranta-Aho, O.; Riekkola, M. Determination of lycopene in food by on-line SFE coupled to HPLC using a single monolithic column for trapping and separation. J. Chromatogr. A 2004, 1052, 25-31.

4. Khachik, F.; Carvalho, L.; Bernstein, P.S.; Muir, G.J.; Zhao, D.; Katz, N.B. Chemistry, distribution and metabolism of tomato carotenoids and their impact on human health. Exp. Biol. Med. 2002, 227, 845-851.

5. Barba, A.I.O.; Hurtado, M.C.; Mata, M.C.S.; Ruiz, V.F.; Tejada, M.L.S. Application of a UV-Vis detection-HPLC method for a rapid determination of lycopene and beta-carotene in vegetables. Food Chem. 2006, 95, 328-336.

6. Nieto-Lopéz, M.J.; Costa, J.; Peiro, E.; Méndez, E.; Rodrigues-saiz, M. Biotechnological lycopene production by mated fermentation of Blakeslea trispora. Appl. Microbiol. Biotechnol. 2004, 66, 153-159.

7. Kerr, S.; Calé, C.; Cabral, J.M.S.; van Keulen, F. Factors enhancing lycopene production by a new Mycobacterium aurum mutant. Biotechnol. Lett. 2004, 26, 103-108.

8. Anonymous. Rapid growth anticipated for canthaxanthin \& lycopene usage. Focus Pigment 2003, 6,3 .

9. Stahl, W.; Sies, H. Bioactivity and protective effects of natural carotenoids. Biochim. Biophys. Acta 2005, 1740, 101-107.

10. Shi, J.; Le Maguer, M. Lycopene in tomatoes: Chemical and physical properties affected by food processing. Crit. Rev. Food Sci. Nutr. 2000, 40, 1-42.

11. Zelkha, M.; Ben-Yehuda, M.; Hartal, D.; Raveh, Y.; Garti, N. Industrial processing of tomatoes and lycopene extraction. WO Patent 97/48287, 1997.

12 Dumas, Y.; Dadomo, M.; Di Lucca, G.; Grolier, P. Review: Effects of environmental factors and agricultural techniques on antioxidant content of tomatoes. J. Sci. Food Agric. 2003, 83, 369-382.

13. Brandt, S.; Pék, Z.; Barna, E.; Lugasi, A.; Helyes, L. Lycopene content and colour of ripening tomatoes as affected by environmental conditions. J. Sci. Food Agric. 2006, 86, 568-572.

14. Sharma, S.K.; Le Maguer, M. Licopene in tomatoes and tomato pulp fractions. Ital. J. Food Sci. 1996, 2, 107-113.

15. Toor, R.K.; Savage, G.P. Antioxidant activity in different fractions of tomatoes. Food Res. Int. 2005, 38, 487-494.

16. Britton, G.; Gambelli, L.; Dunphy, P.; Pudney, P.; Gildey, M. Physical state of carotenoids in chromoplasts of tomato and carrots: Consequences and bioavailability. In Proceedings of the 2nd International Congress on Pigments in Food, Lisbon, Portugal, 11-14 June 2002.

17. Leoni, C. "Scarti" in the tomato processing industry: A contribution to disentanglement among culls rejected tomatoes. Production rejected and processing waste. Indust. Cons. 1997, 73, 278-290.

18. Al-Wandawi, H.; Abul-rahman, M.; Al-Shaikhly, K. Tomato processing wastes as essential raw material sources. J. Agric. Food Chem. 1985, 33, 804-807.

19. Knoblich, M.; Anderson, B.; Latshaw, D. Analyses of tomato peel and seed byproducts and their use as a source of carotenoids. J. Sci. Food Agric. 2005, 85, 1166-1170.

20. Bruno, T.J.; Castro, C.A.N.; Hamel, J.F.P.; Palavra, A.M.F. Supercritical fluid extraction of biological products. In Recovery Process for Biological Materials; Kennedy, J.F., Cabral, M.S., Eds.; John Wiley \& Sons: New York, NY, USA, 1993. 
21. Saldana, M.A.D.; Zefel, C.; Mohamed, M.S.; Brunner, G. Extraction of caffeine, theobromine and coca butter from brazilian cocoa beans using supercritical $\mathrm{CO}_{2}$ and ethane. Chem. Eng. Trans. 2002, 2, 447-482.

22. Knez, Z.; Skerget, M. Phase equilibria of the vitamins D2, D3 and K3 in binary systems with $\mathrm{CO}_{2}$ and propane. J. Supercrit. Fluids 2001, 20, 131-144.

23. McHugh, M.A.; Krukonis, V.J. Supercritical Fluid Extraction-Principles and Practice; Brenner, H., Ed.; Butterworth-Heinemann: Stoneham, MA, USA, 1994.

24. Rozzi, N.L.; Sing, R.K.; Vierling, R.A.; Watkins, B.A. Supercritical fluid extraction of lycopene from tomato processing byproducts. J. Agric. Food Chem. 2002, 50, 2638-2643.

25. Baysal, T.; Ersus, S.; Starmans, D.A.J. Supercritical $\mathrm{CO}_{2}$ Extraction of beta-carotene and lycopene from tomato paste waste. J. Agric. Food Chem. 2000, 48, 5507-5511.

26. Favati, F.; Pietrafesa, A.; Galgano, F. Extraction of natural antioxidants (carotenoids and tocopherols) from by-products of the tomato processing industry. In Proceedings of the 6th International Symposium on Supercritical Fluids, Versailles, France, 28-30 April 2003.

27. Vasapollo, G.; Longo, L.; Rescio, L.; Ciurlia, L. Innovative supercritical $\mathrm{CO}_{2}$ extraction of lycopene from tomato in the presence of vegetable oil as co-solvent. J. Supercrit. Fluids 2004, 29, 87-96.

28. Sabio, E.; Lozano, M.; Espinosa, V.M.; Mendes, R.L.; Pereira, A.P.; Palavra, A.F.; Coelho, J.A. Lycopene and beta-carotene extraction from tomato processing waste using supercritical $\mathrm{CO}_{2}$. Ind. Eng. Chem. Res. 2003, 42, 6641-6646.

29. Suogi, Z.; Yungxiang, H.; Guopeng, Q.; Renan, W. Extracting lycopene from tomato powders by supercritical propane and carbon dioxide with industrial scale pilot. In Proceedings of the 6th International Symposium on Supercritical Fluids, Versailles, France, 28-30 April 2003.

30. Paolo, A.; Ireneo, K.; Angelo, C.; Alessia, F.; Marisa, T.; Crucil, I. Lycopene extraction from processed tomatoes using supercriticas $\mathrm{CO}_{2}$. In Proceedings of the 7 th Italian Conference on Supercritical Fluids/9th Meeting on Supercritical Fluids, Triest, Italy, 13-16 June 2004.

31. Ollanketo, M.; Hartanen, K.; Riekkola, M.; Holm, Y.; Hiltunen, R. Supercritical carbon dioxide extraction of lycopene in tomato skins. Eur. Food Res. Technol. 2001, 212, 561-565.

32. Nobre, B.P.; Palavra, A.F.; Pessoa, F.L.P.; Mendes, R.L. Supercritical $\mathrm{CO}_{2}$ extraction of trans-lycopene from Portuguese tomato industrial waste. Food Chem. 2009, 116, 680-685.

33. Mendes, R.L.; Nobre, B.P.; Coelho, J.P.; Palavra, A.F. Solubility of Beta-Carotene in Supercritical Carbon Dioxide and Ethane. J. Supercrit. Fluids 1999, 16, 99-106.

34. Nobre, B.P.; Palavra, A.F.; Mendes, R.L. Solubility of Beta-Carotene in Near-Critical Mixtures of (Ethane + Propane). J. Chem. Eng. Data 2002, 47, 1159-1163.

35. Mendes, R.L.; Coelho, J.P.; Fernandes, H.L.; Marrucho, I.J.; Cabral, J.M.S.; Novais, J.M.; Palavra, A.F. Applications of supercritical $\mathrm{CO} 2$ extraction to microalgae and plants. J. Chem. Tech. Biotechnol. 1995, 62, 53-59.

Sample Availability: Samples of the compounds are available from the authors.

(C) 2012 by the authors; licensee MDPI, Basel, Switzerland. This article is an open access article distributed under the terms and conditions of the Creative Commons Attribution license (http://creativecommons.org/licenses/by/3.0/). 